\title{
CN Term Type
}

National Cancer Institute

\section{Source}

National Cancer Institute. CN Term Type. NCI Thesaurus. Code C45773.

The $\mathrm{NCl}$ term type designation for a study code for a drug. 